\title{
DOR E GOZO: RELATOS DE MULHERES JOVENS SOBRE AUTOMUTILAÇÕES'
}

\author{
José Juliano Cedaro² \\ Josiana Paula Gomes do Nascimento ${ }^{2}$
}

\begin{abstract}
Resumo: Este artigo discute a prática da automutilação, destacando os relatos de mulheres jovens (entre 15 e 21 anos), atendidas em um Centro de Atenção Psicossocial (CAPS). Tais atitudes consistem em provocar, de forma consciente, feridas no próprio corpo, como cortes, arranhões, queimaduras ou perfurações, não havendo nessas ações o desejo manifesto de suicídio, embora seja comum aparecerem ideações nesse sentido nas falas das pacientes. Os relatos acerca de tal comportamento são apresentados por meio de fragmentos de falas, registrados após atendimentos psicológicos, que esboçam a descrição dos sentimentos expostos dentro do setting terapêutico. As questões suscitadas são discutidas a partir das concepções psicanalíticas a respeito do gozo e do masoquismo, com ênfase nas proposições de Freud e Lacan, focalizando a seguinte indagação: qual é a função da dor autoprovocada e das marcas corporais autoinflingidas - na dinâmica psíquica das pacientes com histórico de automutilações?
\end{abstract}

Palavras-chave: Automutilação. Masoquismo. Melancolia. Psicanálise. Saúde mental.

\section{Introdução}

No artigo "O problema econômico do masoquismo", Sigmund Freud afirma que há um enigma nessa dinâmica psíquica, pois ela se caracteriza pela transfor-

1 Agradecemos a colaboração de toda a equipe do CAPS, porém, para resguardar o sigilo, não especificaremos o nome da instituição. Pela mesma razão foram alterados os nomes de todas as pessoas citadas no texto.

2 Universidade Federal de Rondônia, Porto Velho-RO, Brasil. 
mação da dor e do desprazer em alvos, invertendo-se a lógica mental de se esquivar primordialmente das fontes de sofrimento, para poder buscar satisfação. Sendo assim, o sistema de proteção, que alerta para os perigos internos e externos ao Eu estaria momentaneamente narcotizado, deixando o sujeito vulnerável. Em função de tal constatação, Freud (1924/2011) chega a afirmar que "o masoquismo nos aparece como um grande perigo" (p. 185), uma vez que o princípio do prazer é o guardião, não apenas da vida psíquica, mas de todo o organismo. Ainda nesse mesmo texto, Freud define o masoquista como aquele que deseja ser tratado como uma criança malcomportada, merecendo ser castigada de forma severa, incluindo humilhações e a obrigação de obediência incondicional. E acrescenta:"Muito mais raramente, e com grandes restrições, veem-se incluídas também as mutilações nesse conteúdo" (Freud, 1924/2011, p. 189).

Tendo como base tais assertivas de Freud, este trabalho procura fazer uma interlocução entre algumas questões psicanalíticas e os relatos de sujeitos que sentem prazer com algumas formas de dor. São relatos de pacientes de um serviço de saúde mental, encaminhadas por médicos psiquiatras para atendimento psicológico em decorrência de agressões desferidas ao próprio corpo - como cortes e arranhões feitos a unha ou usando objetos perfurocortantes.

Daremos destaque às histórias de três mulheres com idade entre 15 e 21 anos, que foram acompanhadas por uma equipe multiprofissional de um Centro de Atenção Psicossocial (CAPS) de Rondônia, cujos relatos focalizam situações de autoagressão provocadas há vários anos, com as famílias tendo demorado a perceber esses sintomas. Elas próprias demonstravam não compreender esse comportamento como um proble$m a$, apesar de o esconderem e procurarem subterfúgios para justificar cortes e hematomas pelo corpo.

A escolha desses casos decorre do fato de essas pacientes apresentarem queixas semelhantes entre si, sendo todas jovens, com comportamentos típicos de adolescentes, atendidas no decorrer de aproximadamente um ano, sobretudo em momentos de crises. Além disso, a literatura especializada - conforme citaremos adiante - menciona uma incidência maior desse comportamento em tal faixa etária, corroborando as observações dos profissionais do CAPS acerca das demandas recebidas por aquela instituição, apesar de não disporem de qualquer levantamento estatístico, sobre o assunto, a partir dos prontuários daquele CAPS.

Dentro desse contexto, este artigo faz um relato de casos atendidos nesse serviço de saúde mental, tendo nas queixas e nas demandas de algumas pacientes o ponto de partida para pensar e discutir a prática da automutilação. 


\section{Automutilações: definições e alguns estudos recentes}

Automutilação é o ato de se machucar intencionalmente, de forma superficial, moderada ou profunda, sem intenção suicida consciente. São atos lesivos contra o próprio corpo, como cortes, perfurações, mordidas, beliscões e espancamentos, feitos a mão ou com o uso de objetos, alegando-se a intenção de aliviar tensões ou outros sentimentos egodistônicos.

Tal comportamento apresenta graus variados: desde lesões leves, como arranhar a pele com as unhas ou se queimar com pontas de cigarros; passando por formas moderadas, como cortes superficiais em braços; e chegando até as mais graves, como a autoenucleação e a autocastração. Outras formas graves de automutilação encontradas são a introdução de corpos estranhos no organismo, como agulhas e a amputação dos lobos da orelha (Alroe \& Gunda, 1995; Bharath, Neupane, \& Chatterjee, 1999).

Trabalhos acadêmicos recentes mostram que a prática da automutilação acontece em diferentes faixas etárias, porém se revela mais frequente entre adolescentes, sobretudo do gênero feminino. Em função dessa constatação, algumas dessas pesquisas focalizaram sites e redes sociais da Internet que trazem espaços para discussões a respeito de comportamentos autoagressivos, com destaque a depoimentos de pessoas acerca desse tipo de comportamento (Arcoverde \& Amazonas, 2011; Dinamarco, 2011; Withlock, Powers, \& Eckenrode, 2006).

Esses trabalhos, ao analisarem o conteúdo das manifestações em espaços virtuais, encontraram correlação dos hábitos de automutilação com as frustrações relativas ao universo das descobertas dos adolescentes, envolvendo uso de drogas, intrigas escolares, isolamento social, crises familiares e as primeiras decepções amorosas.

Renata Arcoverde e Maria Cristina Amazonas (2011) discutem essa questão a partir de Karl Menninger, cujas ideias a respeito de comportamentos de autossabotagem se baseiam na concepção freudiana do Supereu, propondo que os sentimentos de culpa excessivos, oriundos de uma raiva contida, promoveriam agressões autodirigidas. Tais atitudes, sob a forma de automutilações, ajudariam a expiar esses sentimentos ou a amenizá-los.

Adriana Dinamarco (2011) focalizou seus argumentos na tese psicanalítica do outro introjetado, propondo que as ações agressivas autodirigidas seriam uma tentativa de destruir o objeto de amor/ódio internalizado. Sustentada em Menninger (1938/1970) e Laplanche (1987), faz a seguinte afirmação:

a cicatriz torna uma marca da separação do eu e o outro, por isto há uma área erotizada, onde existe a certeza de que o sujeito está vivo. .. ainda que o ato 
seja ferir a si mesmo, o eu estaria identificado com o outro, fragmentado, sem a possibilidade de determinar os limites.... Logo, se mutilar é mutilar o outro.

(Dinamarco, 2011, p. 101)

Marilee Strong (1998) é outra pesquisadora a recorrer às teses de Karl Menninger para pensar comportamentos autoagressivos, concordando com o ponto de vista desse psiquiatra norte-americano, fortemente influenciado pela psicanálise, que diferencia comportamentos automutilatórios do suicídio. Segundo Menninger (1938/1970), em qualquer circunstância, mesmo aparentando uma forma de suicídio atenuada, essas ações de autoagressão seriam uma formação de compromisso, um substitutivo que garantiria a não ocorrência da total autoaniquilação do sujeito. A automutilação seria uma busca da cura ou da autopreservação.

Favazza (1987) também corrobora essa observação, completando que o suicídio é uma saída em direção à morte, um ato de fuga, enquanto a automutilação é uma tentativa de reentrada em um estado de normalidade, como num ato mórbido de regeneração. Uma pessoa que tenta suicídio procura acabar com todos os sentimentos, mas uma pessoa que se mutila procura se sentir melhor. Os sujeitos que se mutilam fariam isso por não saberem lidar com emoções fortes, pressões externas e problemas de relacionamento. Essas ações seriam uma maneira de administrarem sentimentos pela via da atuação, em vez de expressá-las verbalmente, pois o outro a ser destruído, pelo ato agressivo, estaria internalizado. Assim, lesionar-se seria uma forma de amenizar a angústia, gerando simultaneamente dor e prazer.

\section{Relatos de dor, prazer - e gozo}

"Você está destruída.
Você tem o coração quebrado.
Sinta e contemple!
Sua vida inteira passa em frente dos seus
olhos.
O sangue flui.

Essa fala é dirigida para a personagem central de um filme, mas poderia ser a voz, sob delírio, relatada pelas pacientes a respeito do que ouvem - e sentem - nos momentos em que se mutilam. Tal epígrafe, extraída do filme Cisne Negro (Aronofsky, 2010), compõe uma cena que oferece o tom das dificuldades de uma jovem bailarina para atender às demandas 
do seu universo particular - seu mundo interno e o mundo ao seu redor -, retratado num trágico movimento de autodestruição, composto por automutilações, distúrbios alimentares e conflitos no campo sexual, por sua vez alimentados por uma relação ambígua e simbiótica com a mãe.

Num mundo diferente, porém com caminhos e sintomas parecidos, temos Paula, uma jovem de 19 anos, que relaciona automutilação ao comportamento de quem tem um vício - e declara não sentir dor ao se cortar, mas "certo prazer".

Lembra quando disse que nunca ouvia o meu subconsciente? Mentira, ouço sim. Sabe como ouço, na hora da mutilação? Percebi que nessas horas minha mente cria imagens, pessoas, histórias. Conversa comigo, faz de tudo. Tudo que eu gostaria que fosse.

Acredita que venha causando lesões corporais no próprio corpo desde os 4 anos, logo após seus pais se separarem. Nessa época, ela e a mãe foram morar com a avó e outros parentes e criaram, desde aquele momento, um sentimento de posse recíproco, com a vida delas girando uma em torno da outra. No entanto, tamanha simbiose não a impediu de manter em segredo, por anos, os hábitos automutilatórios, com os hematomas sendo vistos como consequências inevitáveis das brincadeiras da infância. Num outro discurso, corrente no meio familiar, as manchas seriam sintomas da alergia a picadas de mosquitos - tão comuns quanto abundantes em lares amazônicos.

Quando tinha 10 anos, sua mãe percebeu que ela pegava uma pinça e ficava por horas furando a pele. Desesperada, não encontrou uma ação assertiva para lidar com a filha e, desde então, oscila entre ações extremadas, como amarrá-la, ou, simplesmente, não fazer nada.

Numa sessão relatou ter "saído com outro cara" após ter se desentendido com o namorado. Enfatizou não terem usado camisinha e isso a fez se lembrar do pai que a abandonou e apareceu em sua escola, uma única vez, furtivamente. E acrescentou: "Acho que gosto só da minha mãe". Foi pedida uma explicação para as associações que estava fazendo. Relatou, então, que sua mãe teve um romance passageiro quando ela tinha 12 anos, tendo ficado grávida. Nesse período, as autoagressões de Paula teriam se intensificado, pois tinha ficado com muita raiva por haver alguém entre ela e a mãe. Batia no ventre materno querendo matar o irmão.

Com o passar do tempo, começou a aceitar a situação e a gostar da ideia de ter um irmãozinho. Entretanto, logo após nascer, o irmão faleceu. Recorda apenas de ele estar muito doente e da mãe sofrendo com a perda. Essas lembranças torturam-na, pois Cristina fotografou o filho morto e desde então deixa essa imagem à mostra sobre uma mesa, apesar de nunca mencionar o assunto. 
Paula relata também conflitos com a avó, que por vezes faz a função paterna na casa, estabelecendo regras e limites - e isso a incomoda. Queixa-se das cobranças para que trabalhe, faça a faculdade de Direito, arranje um namoro sério, porque estaria na idade de casar. Enfim, tenha uma vida:"normal, igual a outras pessoas".

Quando está em casa, passa a maior parte do tempo em seu quarto para evitar discussões, e, além disso, naquele espaço tem tudo que precisa: televisão, computador, Internet. Sai dessa redoma apenas para pegar comida ou ir ao cursinho. Salienta não saber "fazer nada em casa", embora tenha tentado aprender a cozinhar e a lavar suas próprias roupas, mas a mãe e a avó, na maioria das vezes, acabam elas mesmas fazendo, dizendo que Paula não tem jeito para as atividades domésticas. Então, é "melhor deixar elas fazerem isso".

Sobre as autoagressões resolveu procurar ajuda por causa da família, pois os comentários e risos a seu respeito, principalmente da avó, "que faz questão de espalhar pra todo mundo", começaram a incomodá-la. Chegou ao CAPS dizendo estar caindo em si, ganhando consciência do problema, mas não se reconhecendo em tal situação.

Sente ódio de si pelas autoagressões, mas, quando está frustrada, a dor lhe traz alívio e prazer. Por outro lado, quando se corta, fica envergonhada e usa calças compridas e blusas com mangas para esconder as marcas pelo corpo.

Hoje está muito visível o quanto deixei de me importar comigo mesma. Vejo que estou me acabando aos poucos. Perdi a vaidade e com apenas 19 anos eu me matei! Queria conseguir ouvir mais o meu subconsciente, mas estou o tempo todo correndo dele. Agora ouço zumbidos do aspirador de pó, toc-toc de sapatos, rangidos de portas, minha cadeira se movendo...

Submersa nesse mesmo tipo de discurso apresentado por Paula, temos Bruna, uma moça de 17 anos quando foi atendida no CAPS. Sua mãe (Mariana) e uma das irmãs (Clarice) também são pacientes de instituições de saúde mental, e ambas receberam o diagnóstico médico de possuírem distúrbios psiquiátricos graves.

Há prescrições contundentes para usarem psicofármacos, mas nem sempre acatam as ordens ou recomendações da equipe. Suas atitudes refratária em relação ao tratamento, às vezes até mesmo agressivas, compõem um quadro que assusta os profissionais que lidavam com elas no cotidiano da instituição.

Numa visita domiciliar, feita pela equipe do CAPS, a primeira observação registrada foi de que cada uma delas, naquela família, vivia num quarto ou num canto isolado da casa, não havendo interação, exceto em momentos de crises agudas. Bruna passava o dia no quarto, dizendo que 
era para evitar os atritos com uma das irmãs ou com a avó, que é vizinha delas.

Sua mãe, Mariana, tem três filhas, sendo a mais velha adotada, pois, quando se casou, a ginecologista teria dito que não poderia engravidar. Entretanto, ao adotar a filha mais velha, soube que estava grávida de Clarice, que também é paciente de um CAPS da cidade, conforme mencionamos anteriormente. Ela recebeu o diagnóstico de cleptomania e apresenta histórico de uso de drogas e também de automutilações, assim como Bruna.

Clarice e Bruna são filhas de pais diferentes e vivem constantemente em atrito, com ódio mutuamente declarado, muitas vezes chegando a agressões corporais. Mariana, por sua vez, posiciona-se passivamente perante o eterno digladiar das filhas.

Numa das vezes em que Mariana foi chamada ao CAPS, para conversar a respeito do tratamento de Bruna, queixou-se de sua agressividade exacerbada, principalmente quando a filha se vê contrariada. Numa dessas situações, trancou-se no banheiro, pegou um aparelho de barbear descartável, tirou a lâmina e começou a se cortar. Mariana não esboçava desespero ou pedido de ajuda, mas uma enfática cobrança para que o CAPS "desse um jeito em Bruna", pois já havia passado alguns meses desde o início do tratamento e "aquela filha" continuava a lhe "dar trabalho".

Indiferente à postura da mãe, Bruna descreveu o cuidado em cortar os pulsos meticulosamente, para as marcas ficarem todas certinhas, porque acha bonitas as cicatrizes que carrega nos braços. Acrescenta: "Provocar-me dor física, rasgando a pele, me deixa momentaneamente calma. Sinto um enorme prazer".

Esse mesmo cuidado com os cortes, construídos durante horas em um quarto ou banheiro, para tentar aliviar as dores e as angústias, são encontrados nos relatos de outra moça, a quem chamaremos de Marta. Uma jovem de 21 anos, caçula de uma família de cinco irmãos, residente com os pais bastante idosos, parecendo ser neta deles, e não a filha - segundo enfatizava nas sessões.

Relatou várias vezes que resistira muito em procurar ajuda psicológica, mesmo padecendo de uma vida de muitos sofrimentos e mágoas não superadas, por ser uma pessoa muito fechada e não confiar em ninguém.

No início do tratamento, suas queixas se fixavam no fato de ter compulsão por se mutilar. No decorrer das sessões, foi aos poucos falando do martírio de algumas lembranças indeléveis, que carrega desde os 5 anos, quando foi abusada sexualmente.

Com muita dificuldade, mas sempre insistindo que precisava falar, pôde descrever o ocorrido, conforme lembra todos os dias, apesar de nunca ter coragem para compartilhar isso com outra pessoa. Contou que, quando brincava de esconde-esconde com os irmãos, um deles, dez anos 
mais velho, levou-a para um quarto. Ela, mesmo querendo gritar, pedir ajuda, não conseguiu reagir.

Como mora com os pais, sempre encontra esse irmão, que vai muito à casa deles, principalmente nos encontros familiares. Ele costuma estar acompanhado da mulher e dos filhos, sendo sempre gentil e simpático. Marta fica intrigada com esse comportamento dócil, diferente do que esperaria de um molestador. Ela não consegue demostrar carinho, mas também não expressa ódio ou desapreço, limitando-se a não lhe dar atenção. "Meu irmão está lá com a família dele - aparentemente feliz. Ele vai sempre à minha casa, e, assim, vivo numa angústia constante."

Excessivamente reclusa, queixa-se da solidão e descreve anos em que sofreu em silêncio o fato de se autoagredir de forma compulsiva, acentuando sempre deixar um canivete ao seu alcance, pois se der vontade estará às suas mãos.

Comecei a me cortar quando tinha 14 anos. Senti um desespero sem saber de onde vinha. Estava na cozinha, peguei a faca e dei um corte no meu braço. Senti um alívio daquilo que me atormentava. Então, até hoje essa é a saída que encontro para amenizar meu sofrimento e não consigo parar de fazer isso.

Quando está angustiada, a vontade de se cortar aumenta. Algo frequente - faz questão de salientar -, pois sempre fracassa, mesmo se empenhando muito. Perfeccionista, conforme se avalia, não consegue levar a termo seus planos, ficando sempre frustrada. Numa reação quase automática, volta a se cortar e fica retida num eterno circungirar, voltando sempre ao ponto da solidão e da necessidade de sentir, literalmente na pele, a dor que a ajuda a suportar a angústia de viver.

Nesse percurso, mudou várias vezes de emprego e lamenta não se adaptar nem estabelecer relações de amizade - ou qualquer proximidade com os colegas de trabalho. Tímida, relata nunca ter conseguido apresentar trabalho na escola, e - vez ou outra - isso traz problemas no trabalho, pois não sabe expressar suas vontades e pensamentos, ficando paralisada toda vez que tem de falar em público.

Sabe que as outras pessoas a veem como uma estranha, pois tem poucos amigos ou amigas e não tem namorado. Tem nojo de sexo, não suportando nem mesmo ver qualquer cena insinuante de eroticidade na televisão ou numa foto de revista. Em função disso, acaba se afastando de qualquer pretendente a um romance mais íntimo, como ocorreu quando um rapaz abraçou-a de forma mais intensa. Foi o suficiente para romper o relacionamento, embora viessem mantendo vínculo havia algum tempo.

No decorrer do tratamento, começou a levantar questões e a correlacionar o abuso sofrido ao fato de se mutilar, bem como o horror ao sexo. Questionava o irmão, mas também questionava a si mesma: "Eu poderia ter gritado ou corrido. Não entendo por que deixei aquilo acontecer". Passou 
a verbalizar a raiva do irmão e a culpá-lo pelos caminhos erráticos que sua vida tomou. Enfatiza que ele, aparentemente, tem uma família feliz. Quanto a ela, comenta: "nunca vou ter a minha". Contudo, mais do que o sentimento de raiva para com o irmão, passou a se culpar por não ter reagido; como se tivesse colaborado, optado pelo que aconteceu.

\section{Discussão dos casos}

Nos depoimentos colhidos nos atendimentos, encontramos sentimentos latentes de raiva, mesclados a culpas exacerbadas e prazer perante a dor autoprovocada. Paula, Bruna e Marta descrevem relações de ódio, manifesto ou latente, por pessoas próximas, como familiares e namorados. Marta se refere ao irmão, enquanto com Paula e Bruna a raiva se focaliza em seus respectivos pais, dos quais cada uma, à sua maneira, se queixa por ter sido abandonada. Bruna, inclusive, tinha uma ação na Justiça para tentar aumentar o valor da pensão e ter as mesmas regalias dos filhos do outro casamento do pai."Quero brigar com ele. Que ele pague tudo que deve para minha mãe. Quero que ele me odeie." Dizia isso com ênfase e raiva, e completava: "Se não conseguir o que estou pedindo, vou cortar os pulsos, fazendo jorrar sangue para todo lado, na frente deles. Vai ver se dessa forma ele não vai sofrer". Nessa fala, mais do que raiva, chamava a atenção no prazer em dizer "quero brigar com ele... quero que ele me odeie...quero vê-lo sofrer".

Bruna dizia ter no atual padrasto um aliado, que iria depor a seu favor na audiência judicial pelo aumento da pensão, porém nunca fazia menção a ele em qualquer outra situação. Animava-se em dizer que o grande amor da vida de sua mãe é seu pai biológico, alimentando a esperança de que um dia eles estarão juntos, apesar de todo o ódio manifestado para com o genitor e o discurso de sua mãe (Mariana) não contemplar a menor disponibilidade nesse sentido. Da mesma forma, odeia a irmã (Clarice), com quem briga apenas para defender a mãe, que seria a única pessoa com quem gosta de conviver, pois "ela me entende e faz tudo o que quero". Dizendo isso, fez um esboço num papel dos sentimentos que tem pelas pessoas de sua família:

$$
\begin{aligned}
& \text { Avó }=\text { raiva } \\
& \text { Clarice (irmã) }=\text { raiva } \\
& \text { Irmã adotada }=\text { gosta } \\
& \text { Pai }=\text { ódio } \\
& \text { Mãe }=\text { amor }
\end{aligned}
$$


Nos atendimentos, revelava ter grande apreço por desavenças e pelejas com pessoas que ocupam funções para as quais se costuma manifestar afeições, como ternura e amor. Bastava ser contrariada por elas para se irritar e recorrer a comportamentos agressivos. No entanto, se as intrigas estavam fora da zona familiar, declinava e fugia do embate. Assim, desistiu de ir à escola, pois não se sentia bem lá. E completa:"Como minha mãe não disse nada, nem faço questão de voltar a estudar."

Foi exatamente nesse contexto que as automutilações começaram aos 13 anos, quando entrou em atrito com uma colega e, não conseguindo relevar as trocas de insultos, passou a se cortar. Assim, esse padrão de resposta a qualquer problema inerente à vida - mesmo os mais banais se intensificou e virou hábito."Até hoje, quando tenho vontade de bater ou machucar alguém, faço comigo mesma".

Mais do que apreço por uma intriga, Bruna se regozija em relatar as mutilações, descrevendo os detalhes e os cuidados no ato de se cortar. Acentuava que, em vez da dor, havia uma calmaria para uma alma tão atormentada. Além disso, as cicatrizes se transformavam em marcas pessoais, oferecendo-lhe um diferencial entre os pares, como se o estilete que usava construísse seu estilo - sua idiossincrasia. "Não dói, e isso faz que fique diferente dos meus amigos. Essa é a minha marca!"

Encontramos também esse gozo narcísico, escondido e recluso, nas lamentações de Marta, depositando na dor, em ver o sangue escorrendo, o conforto para suas angústias e o vazio que sobrevém aos fracassos:"O canivete sempre está no meu quarto, escondido, porque, se me der vontade, já está por perto". Quando se corta, esquece inclusive de si própria, de seus problemas, pois este é seu momento de sentir prazer e alívio da angústia que frequentemente lhe invade.

Há, portanto, um forte componente autoerótico nesse tipo de mutilação. Um fechar-se para o mundo, um retornar a um lugar seguro, apesar de perigoso e recheado de sofrimento, como também encontramos no discurso de Paula, conforme podemos ver a seguir:

No momento, no ato, sinto alívio, sinto prazer, mas depois a gente se sente muito mal. Mutilação sempre fez parte da minha vida, bloqueando possibilidades, afetos, impedindo-me de viver. Criei essa Paula que visualmente sou, e escondi a outra, que nas horas de mutilação aparece e vive.

Eis, então, falas melancólicas em essência, tratando das agruras da vida, mas oferecendo a ideia de que há um gozo nisso, tal qual aparece nas falas de Bruna ao descrever os detalhes de quando se retalha em seu quarto ou no banheiro.

No Seminário "A ética da psicanálise", Lacan distingue gozo de prazer, indicando que gozar é um movimento de busca de algo perdido, do 
objeto impossível e fora do significado, consistindo na tentativa permanente de passar dos limites e ir para além do princípio do prazer.

Eis porque podemos conceber que o prazer seja violado em sua regra e em seu princípio, porque ele cede ao desprazer. Não há outra coisa a dizer - não forçosamente à dor, e sim ao desprazer, que não quer dizer outra coisa senão gozo. (Lacan, 1959-60/1997, p. 73)

No texto intitulado "Kant com Sade", em que se propõe correlacionar "a ética do bem", do filósofo prussiano, com a "ética do mal", daquele cuja obra inspirou o termo "sadismo", afirma:

uma prática como a psicanálise, que reconhece no desejo a verdade do sujeito, não pode desconhecer o que virá depois, sem demonstrar aquilo que recalca. $\mathrm{O}$ desprazer é reconhecido aí por experiência como dando pretexto ao recalque do desejo, ao se produzir no caminho de sua satisfação - mas também como dando a forma assumida para essa mesma satisfação no retorno do recalcado. (Lacan, 1963/1998b, pp. 796-797)

Se no desejo está a verdade do sujeito, onde estará o desejo de quem toma o desprazer como meta? Qual é a demanda de quem se mutila? Quem demanda o gozar para quem goza no sofrer?

Ainda no texto "Kant com Sade", Lacan afirma que o gozo, enquanto movimento mortífero, sob o império da pulsão de morte, se mantém graças à subserviência do sujeito a uma ordem superior, à submissão a um Outro absoluto. No Seminário "Mais, ainda", cujo mote central é exatamente discutir esse conceito, indaga: "O que é o gozo?" De imediato, responde com um axioma: "O gozo é aquilo que não serve para nada" (Lacan, 1972-1973/1985, p. 11).

O gozo não serve para nada porque ele reduz o sujeito a uma instância negativa, e seu resultado é o vazio. Com efeito, o gozo não seria da ordem do direito, e sim do dever, pois quem impõe a alguém gozar é o Supereu, tal como afirma Freud em 1924 sobre o masoquismo do Eu, que, submisso a um sadismo superegoico, não consegue escapar de tal condição. Lacan insiste: “Nada força ninguém a gozar, senão o superego ${ }^{3}$. $O$ superego é o imperativo do gozo - Goza!" (Lacan, 1972-1973/1985, p. 11).

Podemos deduzir que o gozo nas automutilações é demandado pela incapacidade de se escapar do Outro absoluto ou de um Supereu excessivamente severo, estando o sujeito imerso num quadro melancólico, no qual amor, ódio e culpa se misturam em atos e pensamentos simultâneos de dor e de prazer. Logo, o prazer na dor seria uma concentração

3 Considerando que há várias formas de tradução e de grafia dos conceitos " $E s$ ", "Ich", "Überich", optamos por Id, Eu e Supereu, respectivamente, como faz Paulo Cézar de Souza (2010) e nas traduções feitas por ele da obra freudiana no Brasil. No entanto, serão respeitadas as grafias originais nas citações ipsis litteris. 
de investimentos narcísicos operando a perda de um objeto perdido e a saudade de um lugar e um tempo vivenciados apenas no imaginário.

Essa função da dor autoerótica, concentrada no Eu, sendo peculiar à melancolia, é abordada por Freud em várias obras, inclusive no artigo “Luto e melancolia", de 1917, no qual mostra que há um autoerotismo na dor, tanto nas psicopatologias narcísicas quanto nas neuroses transferenciais, mas que, nas primeiras, os sintomas são mais intensos e menos flexíveis.

O automartírio claramente prazeroso na melancolia significa... a satisfação de tendências sádicas e de ódio relativas a um objeto, que por essa via se voltaram contra a própria pessoa. . . através do rodeio da autopunição, vingar-se dos objetos originais e torturar seus amores por intermédio da doença, depois que se entregaram a ela para não ter de lhes mostrar diretamente sua hostilidade. A pessoa que provocou o distúrbio afetivo do doente, e para a qual está orientada sua doença, normalmente se encontra no círculo imediato dele. Assim, o investimento amoroso melancólico em seu objeto experimentou um duplo destino: parte dele regrediu à identificação, mas outra parte, sob a influência do conflito da ambivalência, foi remetida de volta ao estágio do sadismo, mais próxima desse conflito. (Freud, 1917/2010b, p. 184)

A regressão ao estágio do sadismo, mencionado na citação anterior, correlaciona-se ao masoquismo primário, apresentado por Freud como resposta à indagação sobre "o porquê" e "como" a dor se torna uma meta, invertendo a lógica da função protetora do Eu. O masoquismo secundário, como um destino possível das pulsões, seria oriundo de um momento primitivo no desenvolvimento da psiquê, antecedente a uma hipotética situação em que as pulsões básicas ainda não teriam se mesclado. Quando ocorre tal fusão, a libido promoveria um refreamento da pulsão de morte. No entanto, defende Freud, a fusão pulsional geraria resíduos, fazendo que partes da energia tanatogênica escapem ao amansamento promovido pela ligação com Eros.

pode-se dizer que... o sadismo primordial...é idêntico ao masoquismo. Depois que sua parte principal foi transposta para fora, para os objetos, permanece no interior, como seu resíduo, o masoquismo propriamente erógeno, que, por um lado, tornou-se componente da libido, e, por outro lado, ainda tem seu próprio ser como objeto. Esse masoquismo, então, seria testemunha e sobrevivência daquela fase da formação em que sucedeu o amálgama, tão importante para a vida. (Freud, 1924/2011, p. 192)

A dor é um fenômeno que ajuda a entender o limiar entre prazer e desprazer, pois tal experiência está na fronteira entre essas sensações. A dor está ligada às pulsões, no sentido de que ela vincula o campo somá- 
tico e o campo psíquico, tendo a função de alerta. É produto do exagero de excitação que invade o campo psíquico, numa grande quantidade de energia, e estando muito acumulada no organismo, não tendo sido descarregada adequadamente, pode paralisá-lo, tal qual a angústia não elaborada. Assim, ao invés de uma defesa, para evitar um problema maior, a dor em excesso se torna o problema em si (Freud, 1895/1990; Lacan, 1959-1960/1997).

E quando a dor se relaciona com o prazer?

Nesses casos, mesmo em eventos cotidianos, nem sempre sabemos onde termina uma e onde começa o outro. Beijo, abraço, cócegas ou uma massagem, entre vários exemplos de toque corporal, podem ser experiências prazerosas ou dolorosas, dependendo não só da intensidade, mas do momento, do ritmo e de outros elementos que possam estar envolvidos. Se pensarmos numa relação sadomasoquista, temos o limiar entre dor e prazer ampliado - estando o elemento guardião da vida narcotizado, conforme as palavras de Freud (1924/2011), pois a dor deixa de ser um alerta e passa ser uma meta pulsional.

Então, como pensar essa questão quando a dor é autoinfligida?

Em tais situações, pelo menos aparentemente, aquele que se filia à dor prescinde do outro para fazê-lo sofrer e gozar dessa dor, como é o caso de quem se mutila. Trata-se, portanto, de algo diferente do vínculo sádico-masoquista, pois nessas parcerias há partes ocupando, fixa ou alternadamente, posições ativas e passivas, nas quais há a expectativa de punição (ou de se projetar em alguém sendo punido), sofrendo pelas "mãos" de uma pessoa amada (Freud, 1919/2010a; 1924/2011).

As automutilações, assim como outro comportamento autoagressivo, seriam consequências dessa energia da pulsão de morte que não foi amansada pela libido, tendo o próprio Eu como alvo de investimento. Para que isso aconteça, seria preciso haver fixações em momentos específicos do desenvolvimento e intensificações de conflitos internos entre as forças psíquicas, tal qual ocorre em qualquer psicopatologia. No tema em questão, o conflito estaria (1) na ausência da função paterna enquanto metáfora, que deveria fazer o corte das simbioses mãe-filha, ou (2) na sujeição de um Eu frágil e masoquista a um Supereu sádico, alimentado por um sentimento de culpa não elaborado. Em ambas as situações, há um embate contra um Outro absoluto, internalizado, mas, diante da impotência egoica em se livrar dessa condição, a agressividade volta contra si, como ocorre com Marta, que enfrenta solitariamente uma história de desamparo e culpa com as lembranças de abuso. Assim, padece e goza autoeroticamente, sob as ordens de um Supereu impiedoso.

Em outra condição, teríamos Bruna e Paula, simbioticamente grudadas em suas mães, a quem declaram ser o único objeto de amor, com ódio manifesto ao pai, por tê-las abandonado. Na realidade, podemos supor que o pai "nem existe, não vale nada", como disse Paula. A mãe é o 
ser absoluto que suscita sentimentos inconscientes, logo inconfessos, de amor-ódio.

Num escrito de 1973,“O aturdido", Lacan afirma que a relação mãe-filha é sempre devastadora, pois o lugar da maternidade e o desejo da mãe, conforme havia proposto no Seminário 17, deveriam ser comparados a um crocodilo e sua bocarra, pois sempre fazem estragos:

O papel da mãe é o desejo da mãe. É capital. O desejo da mãe não é algo que se possa suportar assim, que lhes seja indiferente... Não se sabe o que the pode dar na telha, de estalo fechar sua bocarra. O desejo da mãe é isso. (Lacan, 19691970/2002, p. 105)

De tal maneira, o poder da maternidade corresponde a um Outro primordial, absoluto, pois sua função é suprir as necessidades mais básicas, como fome, sede e aconchego, de tal forma que a criança lhe é totalmente dependente, numa relação de poder "desigual", como definiu Lacan (1960/1998a).

Quem faz a maternagem sentencia sobre tudo o que se refere à existência e às necessidades do filho. Usando as palavras de Colette Soler (2005), a criança se torna uma boneca erótica "com que gozar e a que fazer gozar" (p. 93). A devastação materna se sustenta também na força da fala e seus enigmas. Ao sujeito, que ainda é um mero objeto da opacidade desse gozo, resta interrogar, ou tentar adivinhar, o que se quer dele, ou seja, tentar decifrar o indizível do desejo desse Outro primordial. Em outras palavras, "significar, além de seus ditos, através de suas contradições, seus silêncios, seus hiatos ou seus equívocos, tudo o que ela não diz, mas dá a entender aos seus ouvidos atentos" (Soler, 2005, p. 95).

Para impedir que a criança seja devorada (ou devastada), Lacan (1963/1986) propõe que é preciso a entrada do Nome-do-Pai - a necessária intervenção de uma metáfora que ocupe a função paterna, interditando a alienação ao gozo absoluto, oferecido pela maternagem. "Não se trata apenas em falar em interdições, mas simplesmente de uma dominância da mulher na condição de mãe... os meios de gozo são abertos pelo seguinte princípio - que ele tenha renunciado ao gozo fechado e alheio, à mãe" (Lacan, 1970/2002, pp. 73-74).

Essa renúncia ao gozo fechado, e alheio à mãe, não é encontrada nas histórias de Paula e Bruna. De forma muito parecida, também não é vista na personagem Nina Sayers, do filme Cisne Negro, usado para ilustrar os casos analisados neste artigo. A personagem e as pacientes se posicionam de maneira infantilizada, dependentes. Em alguns momentos tentam se livrar, mostrando querer amadurecer. Mas, em outros momentos, estão às voltas na relação simbiótica e ambivalente com suas mães, presas na zona de conforto de seus quartos, como se fosse uma extensão do útero de suas genitoras. 
Na falta de um corte paterno, que as colocaria fora da relação simbiótica com a mãe, são elas que se cortam. Cortam na pele e sentem prazer na dor e no fluir do sangue. Gozam o gozo do Outro e não numa relação objetal, pois esta última depende de uma intermediação por fantasias, e não por delírios, como é o caso dessas moças.

\section{Concluindo}

Em 1901, no livro Psicopatologia da vida cotidiana, num trecho recheado com um tom meio sádico, Freud descreve situações em que ouvia a lamúria de um familiar por ter mordido a língua ou imprensado o dedo na porta, cuja resposta dele não era um afago ou outro gesto de condolências, mas a pergunta: "Por que você fez isso?". Descontado o chiste, percebemos, também fora da clínica, Freud mostrando o compromisso ético da psicanálise para com a verdade do sujeito. E, como se enfatizasse o lugar do novo saber por ele criado, disparou:"Sei agora, e posso provar, com exemplos convincentes, que muitos ferimentos aparentemente acidentais. .. são, na realidade, lesões autoinfligidas" (Freud, 1901/1987, p. 161).

Nessa busca pela verdade do sujeito que se propôs pensar o enigma das automutilações a partir do olhar psicanalítico, partindo especificamente da pergunta acerca da função da dor e das marcas corporais autoinfligidas para a dinâmica psíquica das pacientes acompanhadas no CAPS, propomos que uma possível resposta a essa questão seja perceber esse fenômeno a partir da tese freudiana sobre melancolia, ou seja, como uma psicopatologia narcísica, com a regressão da libido para o Eu e marcada por sentimentos ambivalentes em relação a um objeto de amor perdido. As automutilações seriam consequências de resíduos de um masoquismo primário, manifestadas dentro de um quadro melancólico, uma vez que carrega todas suas características, como: 1 ) a nostalgia pela perda do objeto de amor; 2) ambivalência de sentimentos para com esse objeto, mesclando amor e ódio, em discursos e atos; 3) regressão e recoIhimento pulsional, manifestado no autoerotismo das agressões dirigidas ao próprio corpo, como se fosse uma masturbação regida pelo império de Tânatos.

Há de se considerar também o caráter deliberado e compulsivo das automutilações enquanto uma passagem ao ato. Diferencia-se, portanto, da condição involuntária das autoagressões e autossabotagens de que trata Freud em "Psicopatologia da vida cotidiana", quando discute sintomas peculiarmente neuróticos, em que há uma formação de compromisso entre o desejo e as defesas, sendo algo corriqueiro, não necessariamente considerado um distúrbio. Posteriormente, Menninger (1938/1970) 
mostrou que as autoagressões são comportamentos frequentes, cuja concepção para cada caso, percebendo-os como um problema de saúde mental (ou não), depende do grau e da intensidade das ações. Sendo assim, quando comparadas às autossabotagens e às autolesões involuntárias, as automutilações seriam um grau mais severo e mais perigoso dentre as agressões "do homem contra si mesmo", embora menos grave do que uma tentativa consciente de suicídio.

As automutilações seriam, portanto, manifestações consequentes de fixações pulsionais a um masoquismo primário e de um Eu deveras frágil para contrapor às demandas de um gozo materno, cujo vínculo não foi totalmente rompido; ou que está submerso a um sadismo superegoico. De tal forma, o comportamento de se autoagredir se sustentaria no gozo autoerótico de um corpo fragmentado e numa estrutura egoica pueril, pois o sujeito nessas condições encontraria dificuldade de investir pulsões para além de si, ou seja, nos objetos e nos ideais, como deve ocorrer quando se rompe/supera o narcisismo primário.

Podemos dizer, então, que as meninas/moças que protagonizaram este trabalho estariam absorvidas numa condição melancólica, que é ao mesmo tempo "tão interessante" e "tão perigosa", como bem definiu Freud no famoso texto metapsicológico de 1917. E, ao cortarem a própria pele, evidenciariam o interessante/perigoso universo em que estão presas, mas por meio dessa ação esboçam um pedido de socorro e uma maneira de se sentir e se manter vivas. 


\section{Pain and jouissance: stories of young women and selfmutilation}

Abstract: This paper presents a discussion regarding the practice of self-mutilation, highlighting the stories of young women (between 15 and 21 years old) attending a Mental Health Center. Such attitudes are the act of causing wounds in their own bodies, such as cuts, scratches, burns or perforations, in a conscious way - but, in these actions, there is no desire of suicide, although it is common to notice suicidal ideations in these patients' speeches. The reports about this behavior are shown by fragments of speeches, registered after psychological treatment, which delineate the description of feelings externalized in a therapeutic setting. The questions are discussed from psychoanalytical conceptions about jouissance and masochism, emphasizing propositions by Freud and Lacan, focusing the following issue: what is the function of self-caused pain - and self-injured body scars - for the psychic

dynamics of the patients with self-mutilation history?

Keywords: Self-mutilation. Masochism. Melancholy. Psychoanalysis. Mental health.

\section{La douleur et le jouissance: rapports des jeunes femmes sur l'automutilation}

Résumé: Cet article traite de la pratique de l'automutilation, en soulignant les histoires de jeunes femmes (entre 15 et 21 ans) fréquentant un centre de santé mentale. Ces attitudes sont à causer des blessures dans le corps, comme des coupures, des éraflures, des brûlures ou des perforations pratiquées d'une façon consciente mais, dans ces actions, il n'ya pas de volonté manifeste de suicide, mais il est courant d'idées suicidaires apparaissent dans les discours de ces patients. Les rapports sur le comportement sont présentés avec des fragments de discours, enregistrés après un traitement psychologique, qui délimitent la description des sentiments exposés dans le cadre thérapeutique. Les questions soulevées sont discutées à partir des idées psychanalytiques sur la jouissance et le masochisme, avec un accent sur les propositions de Freud et de Lacan, en se concentrant sur la question suivante: quelle est la fonction de la douleur d'automutilation - et marques corporelles auto-infligées pour la dynamique psychique des patientes ayant des antécédents d'automutilation?

Mots-clés: Automutilation. Masochisme. Mélancolie. Psychanalyse. Santé mentale. 


\section{Dolor y goce: historias de mujeres jóvenes sobre la automutilación}

Resumen: Este artículo analiza la práctica de la automutilación, resaltando las historias de mujeres jóvenes (entre 15 y 21 años) que reciben tratamiento en a un Centro de Salud Mental. Tales actitudes son el acto de causar heridas en sus cuerpos, como cortes, raspaduras, quemaduras o perforaciones, hechas de manera consciente - pero, en estas acciones, no hay deseo manifiesto de suicidio, aunque es común notar ideaciones suicidas en los discursos de estos pacientes. Los informes acerca de este comportamiento se presentan con fragmentos de discursos, grabados después de un tratamiento psicológico, destacando la descripción de los sentimientos externalizados en el ámbito terapéutico. Las cuestiones planteadas se analizan las ideas psicoanalíticas sobre el goce y el masoquismo, con un énfasis en las propuestas de Freud y Lacan, enfocando la siguiente pregunta: ¿cuál es la función del dolor autodaño - y marcas auto-infligidas en el cuerpo - para la dinámica psíquica de los enfermos mentales con un historial de automutilación?

Palabras-clave: Automutilación. Masoquismo. Melancolía. Psicoanálisis. Salud mental.

\section{Referências}

Alroe, C. J., \& Gunda, V. (1995). Self-amputation of the ear: Three man amputated four ears within five months. Australian and New Zeland Journal of Psychiatry, 29, 508-512.

Arcoverde, R. L., \& Amazonas, M. C. (2011). Autolesão deliberada: relatos em comunidades virtuais. In XVI Encontro Nacional da ABRAPSO. Recife. http://www. encontro2011.abrapso.org.br/trabalho/view?ID_TRABALHO=2541

Aronofsky, D. (Direção). (2010). Cisne negro [DVD]. EUA: Fox Films.

Bharath, S., Neupane, M., \& Chatterjee, S. (1999). Terminator: An unusual form of selfmutilation. Psychopathology, 32, 184-186.

Dinamarco, A. V. (2011). Análise exploratória sobre o sintoma de automutilação praticada com objetos cortantes elou perfurantes, através de relatos expostos na internet por um grupo brasileiro que se define como praticante de automutilação (Dissertação de Mestrado). Instituto de Psicologia, Universidade de São Paulo, São Paulo. 
Favazza, A. (1987). Bodies under siege: Self-mutilation and body modification in culture and psychiatry. Baltimore, MD: The Johns Hopkins University Press.

Freud, S. (1987). Sobre a psicopatologia da vida cotidiana. In S. Freud, Edição standard brasileira das obras psicológicas completas (V. Ribeiro, trad., 2a ed., Vol. 6, pp. 13240). Rio de Janeiro, RJ: Imago. (Trabalho original publicado em 1901)

Freud, S. (1990). Projeto para uma psicologia científica. In S. Freud, Edição standard brasileira das obras psicológicas completas (V. Ribeiro, trad., 3a ed., Vol. 1., pp. 387547). Rio de Janeiro, RJ: Imago. (Trabalho original de 1895)

Freud, S. (2010a). Batem numa criança: contribuição ao conhecimento da gênese das perversões sexuais. In S. Freud, Observações psicanalíticas sobre um caso de paranoia relatado em autobiografia: ("O caso Schreber"): artigos sobre a técnica e outros textos (1911-1913) (P. C. de Souza, trad., pp. 293-327). São Paulo, SP: Companhia das Letras. (Trabalho original publicado em 1919)

Freud, S. (2010b). Luto e melancolia. In S. Freud, Introdução ao narcisismo: ensaios de metapsicologia e outros textos (1914-1916) (P. C. de Souza, trad., pp. 170-194). São Paulo, SP: Companhia das Letras. (Trabalho original publicado em 1917)

Freud, S. (2011). O problema econômico do masoquismo. In S. Freud, Obras completas (Vol. 16: O eu e o id, "autobiografia" e outros textos, P. C de Souza, trad., pp. 184202). São Paulo, SP: Companhia das Letras. (Trabalho original publicado em 1924)

Lacan, J. (1985). O seminário. Livro 20: Mais, ainda. Rio de Janeiro, RJ: Jorge Zahar. (Texto original de 1972-1973)

Lacan, J. (1986). Os nomes do pai. Porto Alegre, RS: Cooperativa Cultural Jacques Lacan. (Texto original de 1963)

Lacan, J. (1997). O seminário. Livro 7: a ética da psicanálise. Rio de Janeiro, RJ: Jorge Zahar (Texto original de 1959-60)

Lacan, J. (1998a). Subversão do sujeito e dialética do desejo no inconsciente freudiano. In J. Lacan, Escritos. Rio de Janeiro, RJ: Jorge Zahar. (Texto original de 1960)

Lacan, J. (1998b). Kant com Sade. In J. Lacan, Escritos. Rio de Janeiro, RJ: Jorge Zahar. (Texto original de 1963)

Lacan, J. (2002). O seminário. Livro 17: o avesso da psicanálise. Rio de Janeiro, RJ: Jorge Zahar. (Texto original de 1969-70) 
Lacan, J (2003). O aturdido. In J. Lacan, Outros escritos. Rio de Janeiro, RJ: Jorge Zahar. (Texto original de 1973)

Laplanche, J. (1987). Problemáticas I. Angústia. São Paulo, SP: Martins Fontes.

Menninger, K. (1970). Eros e Tânatos: o homem contra si próprio. São Paulo, SP: Ibrasa. (Trabalho original publicado em 1938)

Soler, C. (2005). O que Lacan dizia das mulheres. Rio de Janeiro, RJ: Jorge Zahar.

Souza, P. C. (2010). As palavras de Freud: o vocabulário freudiano e suas versões. São Paulo, SP: Ática.

Strong, M. (1998). A bright red scream: Self-mutilation and the language of pain. London: Penguin Books.

Withlock, J. L., Powers, J. L., \& Eckenrode, J. (2006). The virtual cutting edge: The internet and adolescent self-injury. Developmental Psychology, 42(3), 407-417. 
José Juliano Cedaro, professor de Psicologia da Universidade Federal de Rondônia. Supervisor em Saúde Mental. Doutor em Psicologia pela Universidade de São Paulo. Endereço eletrônico:cedaro@msn.com

Josiana Paula Gomes do Nascimento, psicóloga e mestranda em Psicologia pela Universidade Federal de Rondônia. Bolsista da CAPES. Endereço eletrônico: josiana paula@hotmail.com 
